Sally L. Crofts MD ChB, Abdul Alzeer MD, Glenn P. McGuire MD, David T. Wong MD, David Charles MD*

\title{
A comparison of percutaneous and operative tracheosto- mies in intensive care patients
}

The aim of our study was to compare the complication rate of convenional surgical and percutaneous dilational tracheostomies performed under general anaesthesia in critically ill patients. Fifty-three consecutive patients whose lungs were mechanically ventilated and who required tracheostomy were randomised to undergo either conventional surgical tracheostomy $(n=28)$ in the operating room or percutaneous dilational tracheostomy $(n=25)$ in the intensive care unit under general anaesthesia. All of the procedures were successfully completed. No deaths were related to the performance of either tracheostomy technique. Three patients in each group required a dressing change for minor bleeding at the tracheostomy site. There was no major bleeding requiring blood transfusion. One patient in each group developed atelectasis detected on chest $x$-ray postoperatively. In the surgical tracheostomy group, there were two patients with cuff leaks, one with a stomal infection and one with a pneumothorax. None of these complications occurred after percutaneous, dilational tracheostomy. We conclude that the low incidence of complications in both groups indicates that percutaneous dilational tracheostomy can be performed as safely in the intensive care unit with general anaesthesia as surgical tracheastomy can be performed in the operating room.

Nous comparons l'̈ncidence des complications causées par la trachéotomie chirurgicale traditionnelle avec celles de la trachéotomie percutanée par dilatation réalisées sous anesthésie générale chez des grands malades. Cinquante-trois patients

\section{Key words}

EQUIPMENT: tracheostomy;

INTENSIVE CARE,

VENTILATION: mechanical.

From the Departments of Anaesthesia and Otolaryngology,*

The Toronto Hospital, Western Division, 399 Bathurst Street,

Toronto, Ontario M5T 2S8.

Address correspondence to: Dr. G. McGuire, Dept of

Anaesthesia, The Toronto Hospital, Western Divișion, 399

Bathurst St, Toronto, Ontario M5T 2 S8.

Accepted for publication 30 April, 1995. consécutifs sous ventilation mécanique dont létat nécessitait une trachéotomie sous anesthésie générale sont répartis pour subir soit une trachéotomie chirurgicale traditionnelle $(n=28)$ en salle d'opération, soit une trachéotomie percutanée par dilatation $(n=25)$ à l'unité des soins intensifs. Toutes les interventions ont été complétées avec succès. Aucun décès en rapport avec une ou l'autre des méthodes n'est survenu. Dans les deux groupes, on a dî changer le pansement de trois patients pour un saignement mineur du site de la trachéotomie. Il n'y a pas eu de saignement majeur nécessitant de transfusions. Dans chaque groupe, on a détecté de l'atélectasie à la radiographie postopératoire. Dans le groupe de la trachéotomie chirurgicale, deux patients ont présenté des fuites au niveau du ballonnet de la canule, un patient a présenté une infection du stoma et un autre a présenté un pneumothorax. Ces complications ne sont pas survenue avec la méthode percutanée. Lincidence faible de complications dans les deux groupes montre que la trachéotomie pencutanée peut être réalisée aussi bien à l'unité des soins intensifs sous anesthésie générale que la trachéotomie chirurgicale en salle d'opération.

Tracheostomy is a common surgical procedure performed on critically ill intensive care patients. Previous reports have documented considerable associated morbidity, with complication rates varying from 6 to $66 \% .^{1-6}$ The reports of mortality associated with tracheostomy range from 0 to $5 \% .4,5$ Over the years, there have been minor modifications of the standard technique which was first described by Jackson in 1909. ${ }^{7}$ Recently a new technique has been developed aimed at minimizing the morbidity and mortality from tracheostomy.

The technique of percutaneous dilatational tracheostomy was first described by Toye and Weinstein in $1969 .^{8}$ Ciaglia renewed interest in this technique in $1985 .{ }^{9}$ Following this, there have been several reports of experiences and modifications of the technique of percutaneous tracheostomy. ${ }^{10,11}$

Hazard et al. in 1988 reported 55 intensive care patients in whom percutaneous tracheostomy was performed 
under local anaesthesia. They concluded that this technique should be considered for use in critically ill patients requiring prolonged mechanical pulmonary ventilation. ${ }^{12}$ In 1991, Hazard ${ }^{13}$ went on to compare two groups of intensive care patients who had tracheostomies performed by either the conventional surgical approach in the operating room (OR) or percutaneous dilatational technique in the intensive care unit (ICU). These procedures were conducted under local anaesthesia with intravenous sedation. Perioperative complications of haemorrhage, stomal infection and pneumothorax occurred in $46 \%$ of the surgical group and in only $13 \%$ using the dilational technique.

Various modifications of percutaneous dilatational tracheostomy have evolved to aid correct needle and subsequent tube placement within the trachea. These include visualization of the inside of the trachea by a fibreoptic bronchoscope and the use of an endotracheal ventilation catheter. This is to avoid the potential risk of unintentional extubation whilst sharing the airway or the impalement of the needle and guidewire through the endotracheal tube. ${ }^{14-16}$

The proposed benefits of the percutaneous route of tracheostomy are of reduced transport risks as this is a bedside procedure not requiring transfer to the operating room, rapid insertion with decreased bleeding and a possible decreased infection rate. ${ }^{13,17}$

The aim of our study was to compare the complication rate and surgical conditions of conventional surgical and percutaneous dilational trachestomies performed under general anaesthesia in critically ill patients.

\section{Methods}

Approval was obtained from the hospital Ethical Research on Human Subjects Committee. Consecutive patients requiring tracheostomy as an elective procedure in either the medical/surgical or neurosurgical intensive care units of The Toronto Hospital, Western Division were recruited. Informed consent was obtained from the patient or the patient's family if the patient was not mentally competent. They were then randomized to undergo either surgical or percutaneous tracheostomy by alternating weeks.

Exclusion criteria included children $<16 \mathrm{yr}$, enlarged thyroid gland, previous tracheostomy, cervical spine fracture, evidence of coagulopathy defined as platelet count $<100,000 \mathrm{ml}^{-1}$ or prothrombin time $>1.5$ times control.

Patients randomised to conventional tracheostomy underwent general anaesthesia in the operating room. The procedure was performed by the consulting surgical team. The anaesthetic employed was determined by the attending anaesthetist and this was generally a combination of inhaled and intravenous agents.
TABLE I Definition of complications

\begin{tabular}{ll}
\hline Complications & Definition \\
\hline Bleeding - major & $\begin{array}{c}\text { Requiring transfusion or surgical } \\
\text { intervention } \\
\text { Bleeding - minimal }\end{array}$ \\
$\begin{array}{l}\text { Oozing requiring dressing change } \\
\text { Multiple insertions }\end{array}$ & Detected by postoperative chest $x$-ray \\
Subcutaneous emphysema & Detected during the first 24 hr by chest \\
& $x$-ray \\
Cuff leak & Requiring change of tracheostomy in first \\
& 24 hr \\
Atelectasis & Detected by postoperative chest $x$-ray \\
Stomal infection & Inflammation, and purulent discharge \\
& requiring antibiotic therapy \\
\hline
\end{tabular}

Patients randomised to the percutaneous group underwent this procedure in the intensive care unit with general anaesthesia administered by an anaesthetist. The procedure was performed by the otolaryngology house staff under the supervision of a staff otolaryngologist using the well described technique for performing percutaneous tracheostomy with the "Ciaglia Percutaneous Tracheostomy Introducer Set" (Cook Canada Inc.) ${ }^{9,19}$

Following induction and maintenance of general anaesthesia using intravenous agents, the patient was positioned in the ICU bed with the head extended and the operative area prepared. The patient's lungs were ventilated with $100 \%$ oxygen. Laryngoscopy was performed and the endotracheal tube was withdrawn under direct vision until the cuff was located just below the vocal cords to minimize the risk of puncture of the endotracheal tube cuff during cannulation of the trachea with the needle. The skin and underlying tissues were infiltrated with local anaesthetic solution (2\% lidocaine) containing 1:100,000 epinephrine as a vasoconstrictor to minimize bleeding at the site of the incision. After making a $1 \mathrm{~cm}$ vertical incision in the midline half way between the thyroid cartilage and the suprasternal notch, the needle and cannula were inserted between the second and third tracheal rings. The tracheal rings were identified by palpating below the cricoid cartilage. Correct positioning was confirmed by easy aspiration of air. The guide wire was then inserted and the percutaneous dilators used until the required size tracheostomy tube (Shiley \#6 or \#8) could be inserted.

All patients had chest $x$-rays performed immediately postoperatively and the following day. These were reviewed by an independent radiologist and compared with the preoperative chest $x$-ray. Complications and adverse events arising during the procedure, immediately postoperatively and throughout the patients continuing care for two weeks were recorded. (Table I).

The results were analysed using the Chi square test for discrete values (sex, tracheostomy complications, three 
month survival, admission diagnosis) and the unpaired Student's $t$ test for continuous values (age, APACHE II, days intubated). All data are reported as mean $\pm S D$. Statistical significance was accepted at $P<0.05$.

\section{Results}

Fifty-three patients were entered into the study, 25 into the percutaneous group and 28 into the surgical group. In all patients the trachea was intubated with either an oral or a nasal tracheal tube and they required prolonged ventilatory support at the time of the procedure. The mean time from tracheal intubation to tracheostomy was 12.5 days in the percutaneous group and 10.5 days in the surgical group. There were no differences between the two groups (Table II). The mean age of the percutaneous tracheostomy group was 59.2 yr with a mean APACHE II score of 16.0. The mean age of the surgical group was $59.4 \mathrm{yr}$ with a mean APACHE II score of 17.5. The patients were followed up at three months and the survival rates were similar.

The major underlying disease processes at the time of admission to the intensive care unit showed no differences between the two groups (Table III). Some patients going on to developed multiple system failure. The high proportion of neurosurgical/neurology is a reflection of the workload of this hospital, which is a tertiary referral centre for neurosurgery and trauma.

Patients undergoing conventional surgical tracheostomies in the $\mathrm{OR}$ received a standard general anaesthetic comprising both intravenous and inhalational agents (thiopentone $1-4 \mathrm{mg} \cdot \mathrm{kg}^{-1}$, fentanyl $1-4 \mu \mathrm{g} \cdot \mathrm{kg}^{-1}$, nitrous oxide $50 \%$ in oxygen and either enflurane $0.5-1 \%$ or isoflurane $0.25-0.75 \%$ ). Muscle relaxation was provided with vecuronium $0.05-0.15 \mathrm{mg} \cdot \mathrm{kg}^{-1}$. Those undergoing percutaneous tracheostomy received intravenous anaesthesia with a combination of thiopentone 2-5 $\mathrm{mg} \cdot \mathrm{kg}^{-1}$, fentanyl 3-8 $\mu \mathrm{g} \cdot \mathrm{kg}^{-1}$ and muscle relaxation with vecuronium $0.05-0.15 \mathrm{mg} \cdot \mathrm{kg}^{-1}$.

All patients received a full size tracheostomy tube (internal diameter 7-9 mm). Few complications occurred in either group. There was no difference in incidence of complications between the groups (Table IV). There were no deaths directly related to the procedure of tracheostomy performed by either technique. More than two attempts at cannulation were required in one patient in each group but, in both, the assigned technique was successfully completed. No patient suffered major bleeding requiring blood transfusion or surgical intervention. The only patient requiring antibiotic therapy for a stomal infection was in the surgery group (Table IV).

\section{Discussion}

In this study, tracheostomy was performed successfully
TABLE II Demographic data, APACHE II, days ventilated, survival data

\begin{tabular}{llll}
\hline & Pencutaneous & Surgical & $P$ value \\
\hline$n$ & 25 & 28 & \\
Age & $59.2( \pm 16.4)$ & $59.4( \pm 18.3)$ & NS \\
Male:female & $12: 13$ & $19: 9$ & NS \\
APACHE II score & $16.0( \pm 6.2)$ & $17.5( \pm 7.9)$ & NS \\
Days intubated & $12.5( \pm 6.3)$ & $10.5( \pm 5.0)$ & NS \\
3 mo survival & $17.0(68 \%)$ & $14.0(50 \%)$ & NS \\
\hline
\end{tabular}

TABLE III Major underlying disease processes

\begin{tabular}{lcc}
\hline & Percutaneous & Surgical \\
\hline Pulmonary & 4 & 3 \\
Neurological & 14 & 17 \\
Cardiovascular & 3 & 6 \\
Multiple trauma & 4 & 1 \\
Gastrointestinal & 0 & 1 \\
\hline
\end{tabular}

TABLE IV Adverse events associated with tracheostomy

\begin{tabular}{lll}
\hline & Percutaneous & Surgical \\
\hline Death & 0 & 0 \\
Bleeding - major & 0 & 0 \\
Bleeding - minor & 3 & 3 \\
Pneumothorax & 0 & 1 \\
Subcutaneous emphysema & 0 & 1 \\
Multiple attempts & 1 & 1 \\
Cuff leak & 0 & 2 \\
Atelectasis & 1 & 1 \\
Stomal infection & 0 & 1 \\
\hline
\end{tabular}

in 53 patients. The two groups were similar in terms of patient demographics and their day 1 APACHE II score. The distribution of the underlying diagnosis was comparable in the two groups. The incidence of both major complications and minor adverse events as low, with no differences between the groups. There were no deaths directly related to the surgical procedure in either group.

A safe technique for tracheostomy with a low complication rate, which can easily be performed in the intensive care unit offers great potential. There are hazards in transporting critically ill patients with the associated risks of accidental disconnection of the breathing circuit or extubation as well as reduced monitoring during transfer. Additional benefits of a bedside procedure in the ICU are the avoidance of operating room delays and surgery being performed late in the day.

All procedures performed by the percutaneous route in this series were performed by the same small group of experienced surgeons. In an attempt to optimise the 
operative conditions provided for all patients, most patients received an opioid, amnesic, general anaesthetic and a muscle relaxant, providing good operating conditions in the ICU.

Infection occurring in this patient population is a major concern. It has been suggested that the low incidence of bleeding and stomal infection associated with percutaneous tracheostomy may be due to the small incision and tight fit of the cannula. This results in tamponade of bleeding sites and decreases in size of the tract for entry of bacteria. ${ }^{13,17,20}$ The only patient in our study who required antibiotic therapy for a stomal infection was in the surgical group. Postoperative blood loss can be difficult to quantify and standardise between studies. To be consistent with others, we took bleeding sufficient to cause haemodynamic instability or requiring blood transfusion as indicative of major blood loss and bleeding requiring simple dressing change as indicative of minor blood loss. No patient in this study required blood transfusion or surgical intervention for haemorrhage. Three patients in each group required a dressing change for minimal oozing. One patient suffered a pneumothorax and postoperative subcutaneous emphysema associated with surgical tracheostomy.

Our low incidence of serious complications and of minor adverse events in both groups is encouraging, indicating that percutaneous dilational tracheostomy can be performed as safely in the intensive care unit as surgical tracheostomy can be in the operating room. We did not address the delayed complications of these two methods of tracheostomy. Hazard ${ }^{13}$ found that delayed healing after decannulation, tracheal stenosis and cosmetic deformity were more common in surgical compared to percutaneous tracheostomies.

In this study, all procedures were performed by experienced surgeons on critically ill patients, whose lungs were ventilated mechanically with airway management and general anaesthesia provided by experienced anaesthetists. Due to the general anaesthesia, laryngoscopy was performed enabling the endotracheal tube to be withdrawn under direct vision until the cuff was located just below the vocal cords. This minimizes the risk of puncturing of the endotracheal tube cuff during cannulation of the trachea with the needle. Due to its simplicity, this method offers an advantage over other techniques. A limitation of this study is that different surgeons were involved. Multiple surgeons performed the conventional tracheostomies. The percutaneous tracheostomies were supervised by one ENT surgeon but technically carried out by several ENT residents.

One other paper ${ }^{21}$ refers to general anesthesia for insertion of percutaneous tracheostomies but does not include a control group. The primary purpose of this study was to demonstrate the feasibility of performing percutaneous tracheostomy. The complications were not shown or analyzed other than in a descriptive fashion.

In summary, there was no difference in incidence of complications between the surgical and percutaneous tracheostomy groups. The logical progression is for continued experience with the technique of percutaneous dilational tracheostomy leading to its more widespread use in intensive care units. General anaesthesia provides safe and optimal surgical conditions for the performance of percutaneous tracheostomy in the intensive care unit.

\section{References}

1 Heffner JE, Miller KS, Sahn SA. Tracheostomy in the intensive care unit Part 1: Indications, technique, management. Chest 1986; 90: 269-74.

2 Stock MC, Woodward CG, Shapiro BA, Cane FD, Lewis $V$, Pecaro B. Perioperative complications of elective tracheostomy in critically ill patients. Crit Care Med 1986; 14: 861-3.

3 Stauffer JL, Olson DE, Petty TL. Complications and consequences of endotracheal intubation and tracheotomy. Am J Med 1981; 70: 65-76.

4 Chew JY, Cantrell RW. Tracheostomy: complications and their management. Arch Otolaryngol 1972; 96: 538-45.

5 Skaggs JA, Cogbill CL. Tracheostomy; management, mortality, complications. Am Surg 1969; 35: 393-6.

6 Glas WW, King OJ Jr, Lui A. Complications of tracheostomy. Arch Surg 1962; 85: 72-9.

7 Jackson C. Tracheostomy. Laryngoscope 1909; 19: 285-90.

8 Toy FJ, Weinstein JD. A percutaneous tracheostomy device. Surgery $1969 ; 65: 384-9$.

9 Ciaglia P, Firsching $R$, Syniec $C$. Elective percutaneous dilatational tracheostomy: a new simple bedside procedure; preliminary report. Chest 1985; 87: 715-9.

10 Paul A, Marelli D, Chiu RC-J, Vestweber KH, Mulder DS. Percutaneous endoscopic tracheostomy. Ann Thorac Surg 1989; 47: 314-5.

11 Cook PD, Callanan V. Percutaneous dilational tracheostomy technique and experience. Anaesth Intensive Care 1989; 17: 456-7.

12 Hazard PB, Garrett HE Jr, Adams JW, Robbins ET, Aguillard RN. Bedside percutaneous tracheostomy: experience with 55 elective procedures. Ann Thorac Surg 1988; 46: 63-7.

13 Hazard P, Jones $C$, Benitone J. Comparative clinical trial of standard operative tracheostomy with percutaneous tracheostomy. Crit Care Med 1991; 19: 1018-24.

14 Karnik R, Winkler W-B, Seelmann O, Havlicek J, Slany J. Bedside percutaneous dilatational tracheostomy with endoscopic guidance: experience in 72 ICU patients. Crit Care Med 1993; 21: S252. 
15 Barba CA, Angood PB, Kauder DR, et al. Endoscopically guided percutaneous dilatational tracheostomy: a safe, easy and cost-saving procedure. Crit Care Med 1993; 21: S251.

16 Cooper RM, Irish JC, Brown DH. A new technique for percutaneous dilational tracheostomies using an endotracheal ventilation catheter. Can J Anaesth 1993; 40: A71.

17 Griggs WM, Myburg JA, Worthley LIG. A prospective comparison of a percutaneous tracheostomy technique with standard surgical tracheostomy. Intensive Care Med 1991; 17: 261-3.

18 Toye FJ, Weinstein JD. Clinical experience with percutaneous tracheostomy and cricothyroidotomy in $100 \mathrm{pa}-$ tients. J Trauma 1986; 26: 1034-40.

19 Anderson HL III, Bartlett RH. Elective tracheotomy for mechanical ventilation by the percutaneous technique. Clin Chest Med 1991; 12: 555-60.

20 Friedman $Y$, Mayer AD. Bedside percutaneous tracheostomy in critically ill patients. Chest 1993; 104: 532-5.

21 Bodenham A, Diament $R$, Cohen A, Webster $N$. Percutaneous dilational tracheostomy. A bedside procedure on the intensive care unit. Anaesthesia 1991; 46: 570-2. 